\title{
KINETIC STUDY OF THE MANGANESE MINE TAILINGS LEACHING BY ORGANIC REDUCTANT IN SULFURIC ACID SOLUTION
}

\author{
A. Abdallah ${ }^{1^{*}}$, EL Kacemi Kacem², EL Ass Khalid ${ }^{3}$, \\ Y. Darmane ${ }^{4}$, K. Said ${ }^{1}$ \\ ${ }^{1}$ Laboratoire Hydrométallurgie et Environnement, Ecole Nationale Supérieure des Mines de \\ Rabat (ENSMR) BP.753, Agdal-RABAT. \\ ${ }^{2}$ Laboratoire Electrochimie et Chimie Analytique, Université Mohammed-V, Faculté des \\ Sciences de Rabat (FSR), Agdal -RABAT \\ ${ }^{3}$ Laboratoire de Métrologie de l'Environnement, Ecole Nationale Supérieure des Mines de \\ Rabat (ENSMR), BP: 753 Agdal-RABAT. \\ ${ }^{4}$ Université Ibn Zohr, Faculté Polydisciplianaire de Ouarzazate, Ouarzazate
}

(Received: June 12, 2015; Accepted: October 3, 2015)

\begin{abstract}
A kinetic study of the leaching of manganese mining residue by sulfuric acid and potassium oxalate has been investigated. The effects of the reaction agitation speed, manganese ore particle size, acid concentration, oxalate concentration and temperature on manganese rate dissolved. The leaching rates are significantly influenced by the reaction temperature, to both concentration oxalate and acid. The observed effects of the relevant operating variables on the leaching rates are consistent with a kinetic model for chemical control. The apparent activation energy for the leaching of pyrolusite has been calculated using the Arrhenius expression and was found to be $(63.7 \pm 2.9) \mathrm{kJ} / \mathrm{mol}$. The experimental results indicate a reaction order of 1.07 for $\left[\mathrm{H}_{2} \mathrm{SO}_{4}\right]$ concentration and 0.96 for $\left[\mathrm{K}_{2} \mathrm{C}_{2} \mathrm{O}_{4}\right]$. It is concluded that the reductive leaching of pyrolusite with potassium oxalate in acid medium is controlled by chemical reaction. The rate expression associated with the dissolution rate of pyrolusite depending on the parameters chosen may be summarized as follows:

$$
1-(1-x)^{1 / 3}=\frac{1.4510^{7}}{r_{0}^{0.82}} \cdot\left[\mathrm{H}_{2} \mathrm{SO}_{4}\right]^{1.07}\left[\mathrm{~K}_{2} \mathrm{C}_{2} \mathrm{O}_{4}\right]^{0.96} \exp \left(-\frac{63735}{R T}\right) \cdot t
$$

Key words: Leaching kinetics modeling, Potassium oxalate, Mining manganese residue, Sulfuric acid leaching.

\section{Introduction}

Manganese is among the world is most widely used metals, ranking fourth after iron, aluminium and copper. Thousands of everyday metallic items require some percentage of manganese in their manufacture; the main ore is pyrolusite, $\mathrm{MnO}_{2}$. In recent years various hydrometallurgical processes have been studied and developed for recovery of manganese from these manganese sources.

Many studies have focused on reductive leaching of manganic-ferrous ores containing tetravalent manganese using organic reductants, including sawdust [1], glucose, sucrose [2], lactose [3], glycerine [4]. Oxalic acid can also be used as a reducing agent for manganese extraction from manganese dioxide ore $[5,6]$. Leaching of manganese ore using oxalic acid-producing microorganisms has been reported [7]. Chemical leaching of Mn ore using oxalic acid may give an insight into bioleaching [8].
\end{abstract}

${ }^{\#}$ Corresponding author: a.alaoui8@gmail.com 
The typical leaching process involves a chemical reductive step, acid leaching of $\mathrm{Mn}(\mathrm{II})$ ores, purification, separation and final recovery processes such as solvent extraction, electrolysis and electrowinning, and other recovery processes $[9 ; 10]$. Sulfuric acid and different reducing agents have been used for leaching of pyrolusite. The most important leaching agents include ferrous iron solution [11], sulfite solution [12; 13], hydrogen peroxide [14] and hydrochloric acid [15].

This work covers part of activities related to tailings and waste-rock management of manganese ore. Samples of manganese mining residue used in this experimental study were obtained from deposit Imini, Morocco. These residues from the treatment plant pyrolusite, have a relatively fine particle size (-710microns) and $\mathrm{Mn}$ content ranging from $31.6 \%$ to $39.2 \%$. All these residues are removed and deposited near the mine.

This paper present the kinetics of reductive leaching manganese pyrolusite contained in these residues with potassium oxalate as a reducing agent in a sulfuric acid medium and system variables on the main leaching rate. The kinetic model and the apparent activation energy were determined.

\section{Materials and methods}

\subsection{Materials characterization}

A representative sample of residue from the Imini mine area of Ouarzazate Province (Morrocco) was supplied by the society Mining (SACEM). The residue as received was thoroughly blended by rolling. Riffled samples were then collected for size distribution, chemical analysis and mineralogical characterization.

Tab1 gives the chemical composition of the sample. X-ray fluorescence spectrometry has also revealed the presence of a number of trace elements such as $\mathrm{K}, \mathrm{Na}$ and $\mathrm{P}$.
Sieve analysis of the ore is reported on Fig.1.

Table 1. Chemical analysis of the manganese ore

\begin{tabular}{|l|l|}
\hline Component & Grade $(\%)$ \\
\hline $\mathrm{MnO}_{2}$ & 56,31 \\
\hline $\mathrm{SiO}_{2}$ & 21,16 \\
\hline $\mathrm{Al}_{2} \mathrm{O}_{3}$ & 7,56 \\
\hline $\mathrm{BaO}$ & 3,92 \\
\hline $\mathrm{CaO}$ & 2,80 \\
\hline $\mathrm{MgO}$ & 1,80 \\
\hline $\mathrm{K}_{2} \mathrm{O}$ & 1,22 \\
\hline $\mathrm{Fe}_{2} \mathrm{O}_{3}$ & 1,08 \\
\hline $\mathrm{Na}_{2} \mathrm{O}$ & 0,16 \\
\hline $\mathrm{P}_{2} \mathrm{O}_{5}$ & 0,04 \\
\hline $\mathrm{Pb}$ & 2,04 \\
\hline
\end{tabular}

The Imini manganese ore is characterized by the presence of a colloidal highly hydrated $\mathrm{MnO}_{2}$ gel, while crystalline phases include silicate gangue minerals (albite, anorthite, quartz, etc.), though a few peaks are attributable to manganese dioxide minerals (pyrolusite, psilomelane and manganomelane) [16].

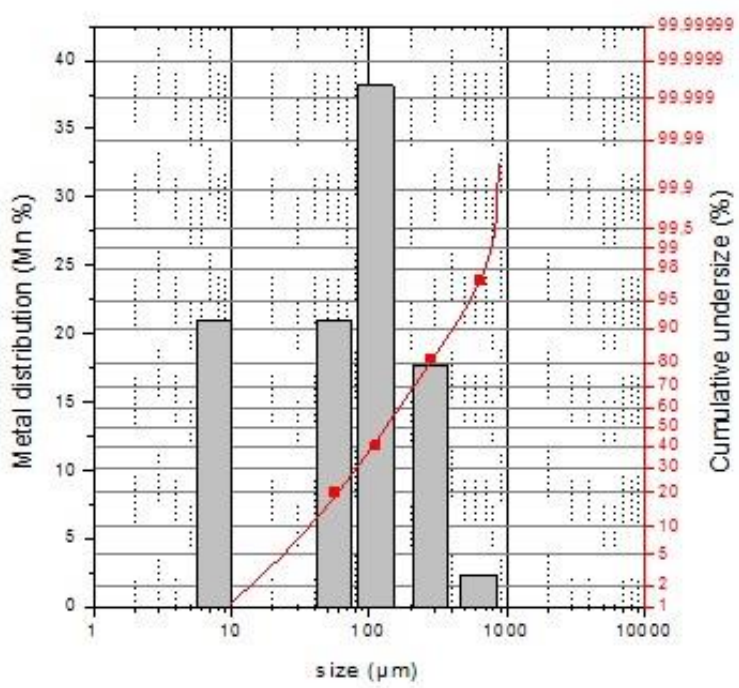

Figure 1. Sieve and Chemical analysis of the manganese ore 


\subsection{Leaching tests}

The dissolution of manganese is due to reduction of its dioxide by potassium oxalate. The reduction [10] between $\mathrm{MnO}_{2}$ and potassium oxalate in acid medium may be given as follows:

$$
\mathrm{MnO}_{2}+\mathrm{C}_{2} \mathrm{O}_{4}^{2-}+4 \mathrm{H}^{+} \rightarrow \mathrm{Mn}^{2+}+2 \mathrm{CO}_{2}+2 \mathrm{H}_{2} \mathrm{O}(1)
$$

All leaching experiments were carried out in a glass reactor double jacket equipped with a magnetically stirrer, condenser, thermometer, openings for adding the solid sample and a sampling device. This set-up provides stable hermetic conditions and allows heating at constant temperature. The calculated quantities of $\mathrm{H}_{2} \mathrm{SO}_{4}$ and $\mathrm{K}_{2} \mathrm{C}_{2} \mathrm{O}_{4}$ were added to the glass reactor and heated-up to the selected temperature. When the temperature was reached and stirring speed was set. The solid (manganese ore) was added and the reaction commenced. After selected time intervals, the solution samples were taken for chemical analysis, which was carried out by UV-vis spectroscopy (Hach DR-5000) and AAS (Perkin Elmer). Stirring was provided in the range of 0 to $1250 \mathrm{rpm}$, temperatures of 25 to $40^{\circ} \mathrm{C}$, leaching times of 5 to $30 \mathrm{~min}$, while the particle size fraction leached was $-630 \mu \mathrm{m}$. The $\mathrm{H}_{2} \mathrm{SO}_{4}$ and $\mathrm{K}_{2} \mathrm{C}_{2} \mathrm{O}_{4}$ concentrations were in the range of $0.25-1 \mathrm{M}$ and $0.06-0.25 \mathrm{M}$, respectively. The phase ratio was $20-120 \mathrm{~g}$ concentrate in $1000 \mathrm{ml}$ of the solution.

\subsection{Effect of parameters}

\subsubsection{Agitation effect}

The effect of agitation on the leaching of pyrolusite was investigated in solution of $\mathrm{K}_{2} \mathrm{C}_{2} \mathrm{O}_{4} / \mathrm{H}_{2} \mathrm{SO}_{4}$ with the $630 \mu \mathrm{m}$ fraction of the manganese ore at $25^{\circ} \mathrm{C}$, using stirring speeds of in the range $0-1250 \mathrm{rpm}$ and solid-toliquid ratio $\mathrm{S} / \mathrm{L}=50 \mathrm{~g} / \mathrm{L}$.
The results indicate that the extraction rate of manganese firstly increases with the increase in stirring speed till $500 \mathrm{rpm}$ then becomes almost independent of the stirring speed with further increase. High stirring speed reduces the thickness of the diffusion boundary layer. Therefore, subsequent experiments were performed at a stirring speed of $500 \mathrm{rpm}$ to ensure that the influence of the external mass transfer is negligible. In this case, solid particles remain suspended in solution homogeneously Fig. 2.

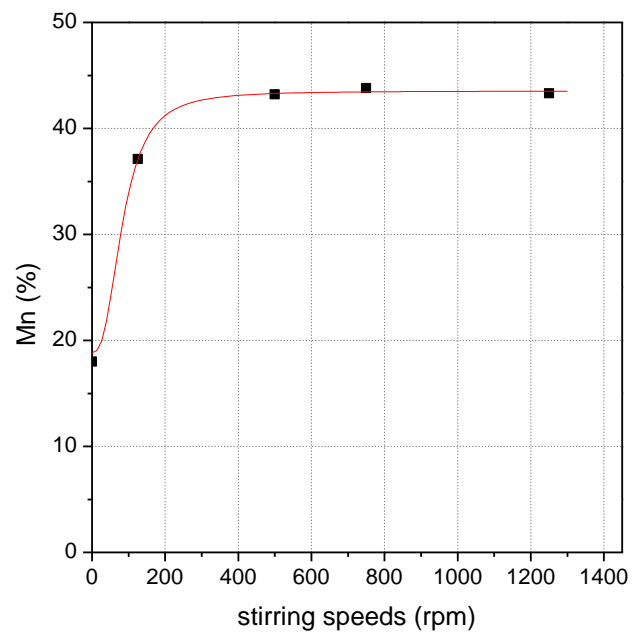

Figure 2. Influence of stirring speed on dissolution from manganese.Conditions: $0.5 \mathrm{M}$ $\mathrm{H}_{2} \mathrm{SO}_{4}, 0.25 \mathrm{M} \mathrm{K}_{2} \mathrm{C}_{2} \mathrm{O}_{4}, 25^{\circ} \mathrm{C} ; 50 \mathrm{~g} / \mathrm{L} ; 30 \mathrm{~min}$.

\subsubsection{Effect of manganese ore particle size}

The effect of particle size on the dissolution of manganese was investigated in $\mathrm{K}_{2} \mathrm{C}_{2} \mathrm{O}_{4}$ solution at $25^{\circ} \mathrm{C}$, using four particle sizes, namely, $-630 \mu \mathrm{m},-280 \mu \mathrm{m},-125 \mu \mathrm{m}$, and $-63 \mu \mathrm{m}$. The results obtained show that the leaching rate very slightly increases by the decrease in the original particle size of pyrolusite, while the increase of manganese dissolved is relatively high for particle size less than $63 \mu \mathrm{m}$. 
This behavior can be explained by the significant increase in the solid surface area in contact with fluid with decreasing particle size Fig. 3.

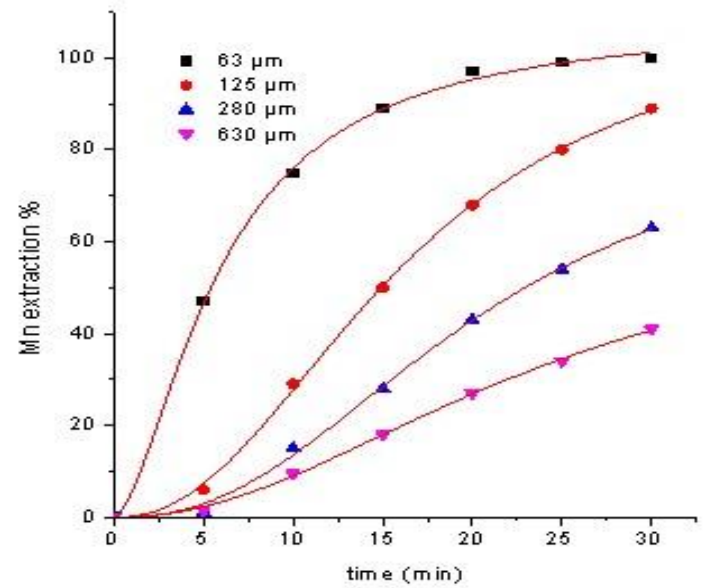

Figure 3. Effect of particle size on the rate of dissolution of the pyrolusite in: $0.5 \mathrm{M} \mathrm{H}_{2} \mathrm{SO}_{4}$; $0.25 \mathrm{M} \mathrm{K}_{2} \mathrm{C}_{2} \mathrm{O}_{4} ; 25^{\circ} \mathrm{C} ; 50 \mathrm{~g} / \mathrm{L} ; 750 \mathrm{rpm}$

\subsubsection{Effect of pulp density}

The effect of solid-to-liquid ratio on the dissolution of pyrolusite was studied in the range of $20-120 \mathrm{~g} / \mathrm{L}$. Fig. 4 shows the effect of this parameter.

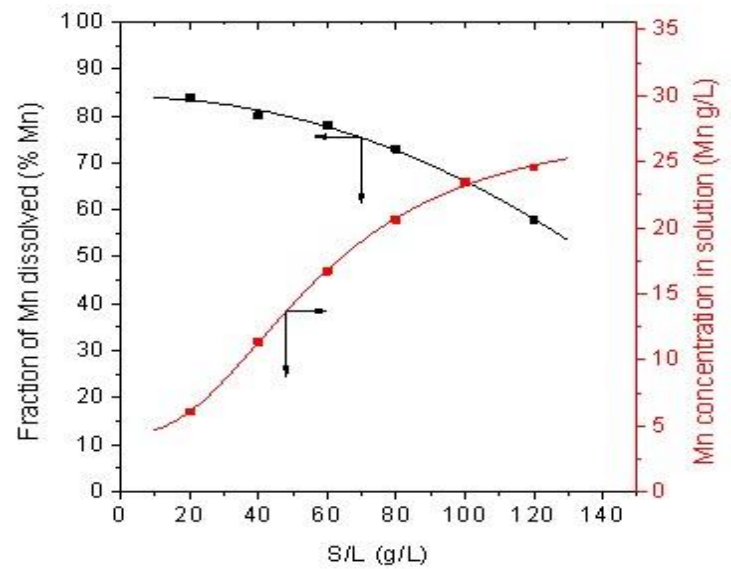

Figure 4. Effect of solid/liquid ratio on the dissolution of manganese under conditions: $1.3 \mathrm{M} \mathrm{H}_{2} \mathrm{SO}_{4} ; 0.4 \mathrm{M} \mathrm{K}_{2} \mathrm{C}_{2} \mathrm{O}_{4} ; 25^{\circ} \mathrm{C} ; 630 \mu \mathrm{m}$; 750rpm; 30min.
As can be seen in Fig. 4, the dissolution of pyrolusite decreases with an increase in solid-to-liquid ratio. This situation can be explained by the increase in the number of pyrolusite particles per amount of reagents in solution.

\subsubsection{Effect of $\mathrm{K}_{2} \mathrm{C}_{2} \mathrm{O}_{4}$ concentration}

The dependence of $\mathrm{K}_{2} \mathrm{C}_{2} \mathrm{O}_{4}$ concentration on the leaching of manganese was investigated at $25^{\circ} \mathrm{C}$ using the $630 \mu \mathrm{m}$ fraction of the manganese ore with solid-toliquid ratio $\mathrm{S} / \mathrm{L}=50 \mathrm{~g} / \mathrm{L}$. The oxalate concentrations used are $0.06,0.09,0.12$, and $0.25 \mathrm{M}$. The recovery of manganese vs. time plots for the different potassium oxalate concentrations given in Fig. 5 show that the recovery of manganese increases with the increase of oxalate concentration.

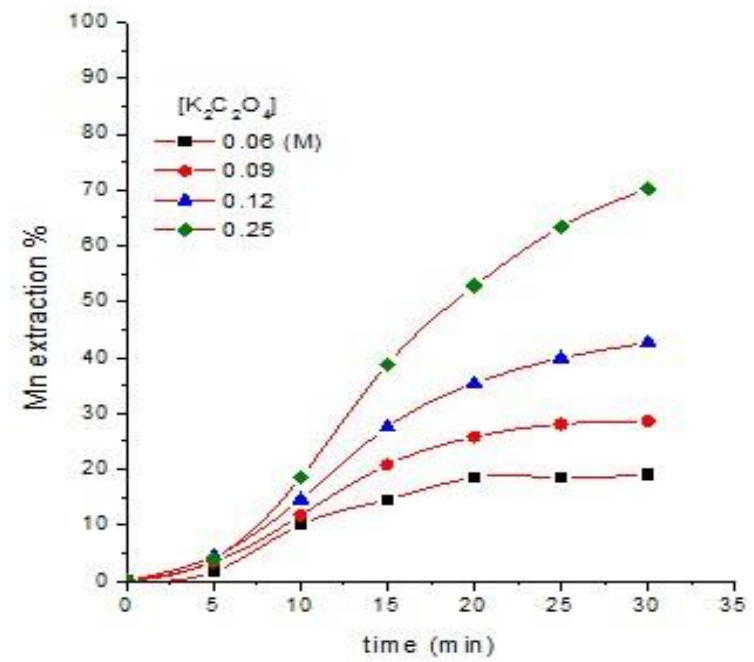

Figure 5. Effect of $\mathrm{K}_{2} \mathrm{C}_{2} \mathrm{O}_{4}$ concentration on the dissolution of manganese, Under conditions: $1 \mathrm{M} \mathrm{H}_{2} \mathrm{SO}_{4} ; 25^{\circ} \mathrm{C} ; 630 \mu \mathrm{m} ; 750 \mathrm{rpm}$

\subsubsection{Effect of $\mathrm{H}_{2} \mathrm{SO}_{4}$ concentration}

The effect of $\mathrm{H}_{2} \mathrm{SO}_{4}$ concentration on the leaching of manganese from its ore was investigated at $25^{\circ} \mathrm{C}$ at $750 \mathrm{rpm}$ stirring speed and solid-to-liquid ratio $\mathrm{S} / \mathrm{L}=50 \mathrm{~g} / \mathrm{L}$. 
The $\mathrm{H}_{2} \mathrm{SO}_{4}$ concentration used was varied from $0.25 \mathrm{M}$ to $1 \mathrm{M}$. The fraction of manganese leached vs. time plots for the different $\mathrm{H}_{2} \mathrm{SO}_{4}$ concentrations was illustrated in Fig. 6.

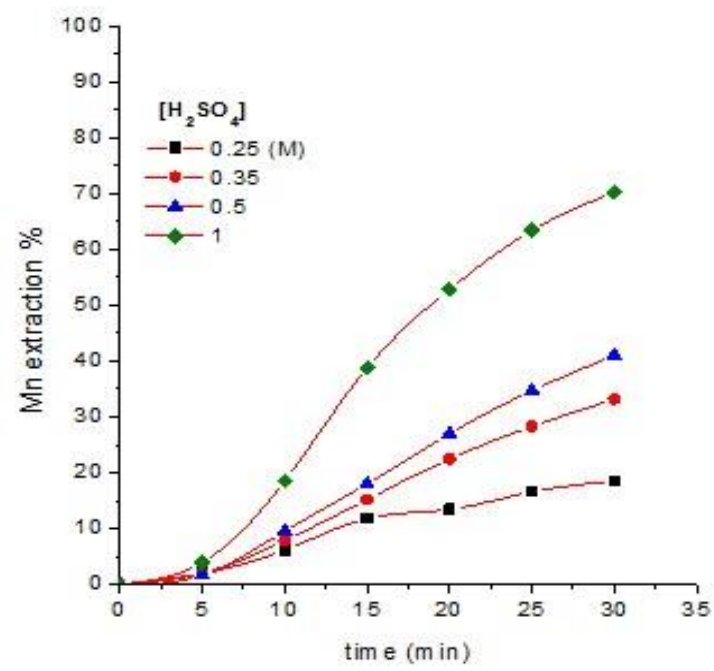

Figure 6. Effect of $\mathrm{H}_{2} \mathrm{SO}_{4}$ concentration on the leaching of pyrolusite under condi-tions: $0.25 \mathrm{M} \mathrm{K}_{2} \mathrm{C}_{2} \mathrm{O}_{4} ; 25^{\circ} \mathrm{C} ; 630 \mu \mathrm{m} ; 750 \mathrm{rpm}$

The concentration of the acid has a significant effect on the leaching of the pyrolusite but in no case was the fraction of manganese extracted more than $84 \%$, value estimated by extrapolation, if the leaching continues for a time greater than $30 \mathrm{~min}$.

\subsubsection{Effect of temperature}

Several leaching experiments were performed at temperatures ranging from $25^{\circ} \mathrm{C}$ to $40^{\circ} \mathrm{C}$ under leaching conditions of $\mathrm{S} / \mathrm{L}=$ $50 \mathrm{~g} / \mathrm{L}, 0.5 \mathrm{M} \mathrm{H}_{2} \mathrm{SO}_{4}$ and at a stirring speed of $750 \mathrm{rpm}$. The results in Fig.7 show that the extent of manganese ore leaching increases significantly with temperature. At $25^{\circ} \mathrm{C}$, only $41 \%$ manganese is leached then increases to about $71 \%$ manganese at $40^{\circ} \mathrm{C}$. The low leaching amounts at low temperature is due to the low reactivity of manganese ore.

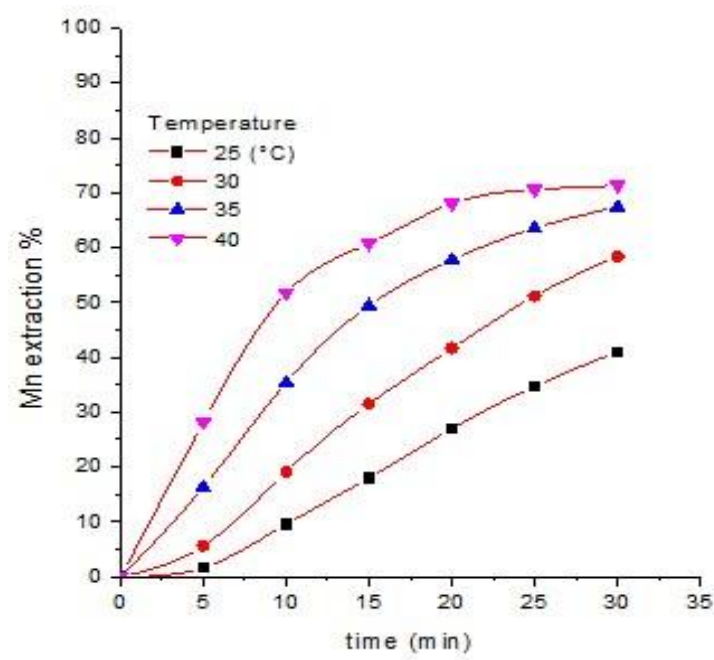

Figure 7. Effect of temperature on the leaching of pyrolusite under conditions: $0.5 \mathrm{M}$ $\mathrm{H}_{2} \mathrm{SO}_{4} ; 0.25 \mathrm{M} \mathrm{K}_{2} \mathrm{C}_{2} \mathrm{O}_{4} ; 630 \mu \mathrm{m} ; 750 \mathrm{rpm}$

\subsection{Discussion of kinetics and kinetic} models

In order to determine the kinetic parameters and the rate-controlling step of the dissolution of manganese in potassium oxalate solutions, the non-catalytic heterogeneous reaction models were performed on the experimental data.

According to these models, the rate of reaction between solid particle and the leaching reagent may be controlled by one of the following steps: diffusion through the fluid film, diffusion through the product layer, or the chemical reaction at the surface. The particle size can stay constant or decrease during the reaction. The rate equations for these models have been introduced in the literature $[17 ; 18 ; 19]$.

$$
\begin{aligned}
& x=\frac{3 b k_{l}}{\beta_{B} r_{0}} C_{A} \cdot t=k_{l}^{\prime} \cdot t \\
& 1-3(1-x)^{2 / 3}+2(1-x)=\frac{6 b D_{e}}{\rho_{B} r_{0}^{2}} \cdot C_{A} \cdot t=k_{d} \cdot t \\
& 1-(1-x)^{1 / 3}=\frac{b k}{\rho_{B} r_{0}} \cdot C_{A} \cdot t=k_{r} \cdot t
\end{aligned}
$$


Where $\mathrm{x}$ is the reacted fraction of pyrolusite, $\mathrm{k}_{\mathrm{l}}, \mathrm{k}_{\mathrm{d}}$ and $\mathrm{k}_{\mathrm{r}}$ are calculated from Eq. (2), Eq. (3) and Eq. (4), respectively.

To obtain the leaching kinetic equation, the experimental data in Figs. 5, 6 and 7 were transformed and fitted to Eq. (3) and (4). The degree of the explanation of these models on the kinetic data was evaluated using correlation coefficient $\left(\mathrm{R}^{2}\right)$ values. The slopes of these plots were used as the apparent rate constants $\left(\mathrm{k}_{\mathrm{d}}\right.$ and $\left.\mathrm{k}_{\mathrm{r}}\right)$. Comparing to the reaction models discussed above, a new variant of the shrinking core model suggested by Dickinson and Heal [20], Equation of this model is given as follows:

$$
\left(\frac{1}{(1-x)^{1 / 3}}-1\right)+\frac{1}{3} \ln (1-x)=k_{m} \cdot t
$$

Where $\mathrm{k}_{\mathrm{m}}$ is the apparent rate constant and $t$ is the reaction time.

Based on this model, the interfacial transfer and diffusion across the product layer both affect the reaction rate.

As can be seen in Tab. 2, after the experimental data were analyzed, it was determined that the chemical reaction controlled model was suitable for this leaching reaction.

The rate constant values and their correlation coefficients are given for the diffusion through the product layer and the chemical reaction controlled models in Tab. 2.

Furthermore, the linear relation between 1$(1-x)^{1 / 3}$ and the reaction time can be seen in Figs. 8, 9 and 11 for the acid concentration, the oxalate concentration and the reaction temperature, respectively.

Finally, the effect of particle size on the rate of pyrolusite dissolution was examined by measuring the reaction rates for four different size fractions $(-63,-125,-280$ and $-630 \mu \mathrm{m})$ is presented in Fig. 10.

In accordance with these results, the equation representing the kinetics of this process was determined to obey the chemical reaction model. Therefore, the rate expression for this process can be written as follows:

$$
\begin{aligned}
& 1-(1-x)^{\frac{1}{3}}=k_{r} \cdot t= \\
& =\frac{k_{0}}{r_{0}} \cdot\left[H_{2} S O_{4}\right]^{n}\left[K_{2} C_{2} O_{4}\right]^{m} \cdot \exp \left(-\frac{E_{a}}{R T}\right) \cdot t(6)
\end{aligned}
$$

Table 2. Correlation coefficients $\left(\mathrm{R}^{2}\right)$ of the kinetic models in different conditions

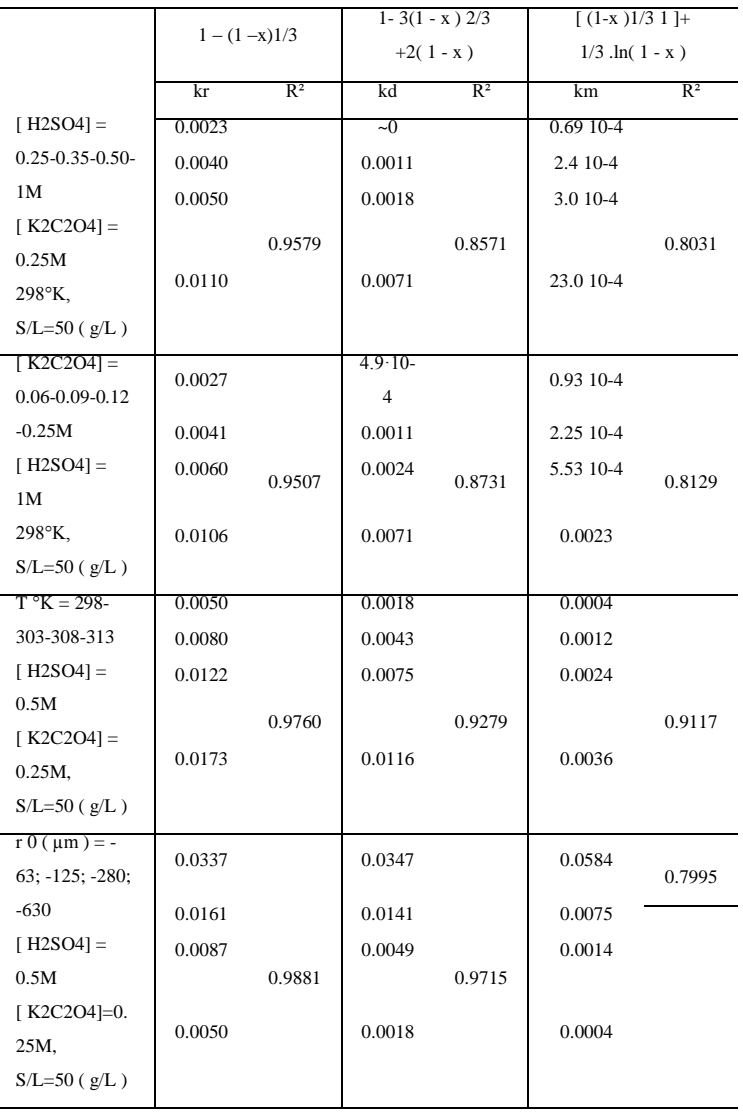

In order to decide the order of reaction with respect to reagent concentration, the results on the effect of $\mathrm{K}_{2} \mathrm{C}_{2} \mathrm{O}_{4}$ and $\mathrm{H}_{2} \mathrm{SO}_{4}$ concentrations, obtained from Figs. 5 and 6 , were applied to this kinetic model, Figs. 8 and 9.

The $\mathrm{kr}$ values for each $\mathrm{H}_{2} \mathrm{SO}_{4}$ and $\mathrm{K}_{2} \mathrm{C}_{2} \mathrm{O}_{4}$ concentrations were determined. From the corresponding $\mathrm{kr}$ and $\mathrm{H}_{2} \mathrm{SO}_{4}$ and $\mathrm{K}_{2} \mathrm{C}_{2} \mathrm{O}_{4}$ concentrations values, plots of $\log \left(\mathrm{k}_{\mathrm{r}}\right)$ versus $\log \left[\mathrm{H}_{2} \mathrm{SO}_{4}\right]$ and $\log \left[\mathrm{K}_{2} \mathrm{C}_{2} \mathrm{O}_{4}\right]$ were obtained. 
As seen from Figs. 8 and 9, the order of reaction was found proportional to power 1.07 of $\mathrm{H}_{2} \mathrm{SO}_{4}$ concentration $\left(\left[\mathrm{H}_{2} \mathrm{SO}_{4}\right]^{1.07}\right)$ and power 0.96 of $\mathrm{K}_{2} \mathrm{C}_{2} \mathrm{O}_{4}$ concentration $\left(\left[\mathrm{K}_{2} \mathrm{C}_{2} \mathrm{O}_{4}\right]^{0.96}\right)$.
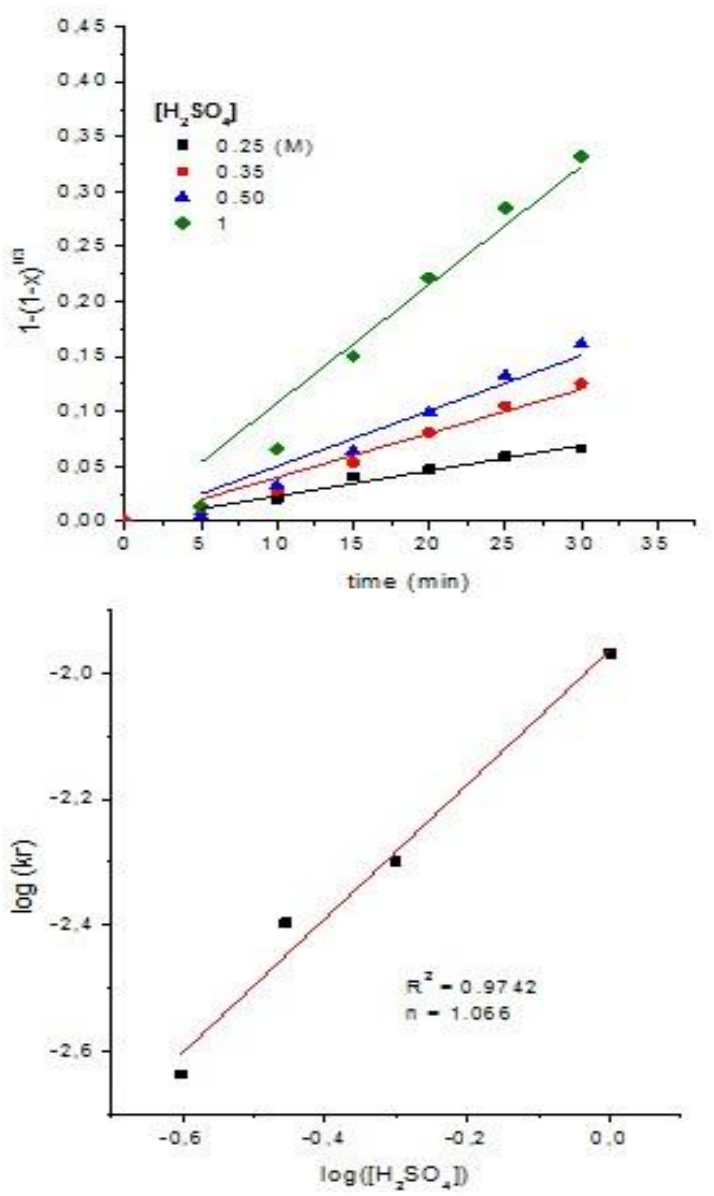

Figure 8. Plots of $1-(1-x)^{1 / 3}$ vs. time for manganese leaching at various; Determination of reaction kinetic order for pyrolusite dissolution with respect to $\mathrm{H}_{2} \mathrm{SO}_{4}$; $\left[\mathrm{K}_{2} \mathrm{C}_{2} \mathrm{O}_{4}\right]=0.25 \mathrm{M} ; 298^{\circ} \mathrm{K} ; \mathrm{S} / \mathrm{L}=50 \mathrm{~g} / \mathrm{L}$

From the analysis of the shrinking core model with chemical reaction control (Eq.3) there appears to be a clear dependence of the model constant, $\mathrm{kr}$ on the inverse of initial particle radius.
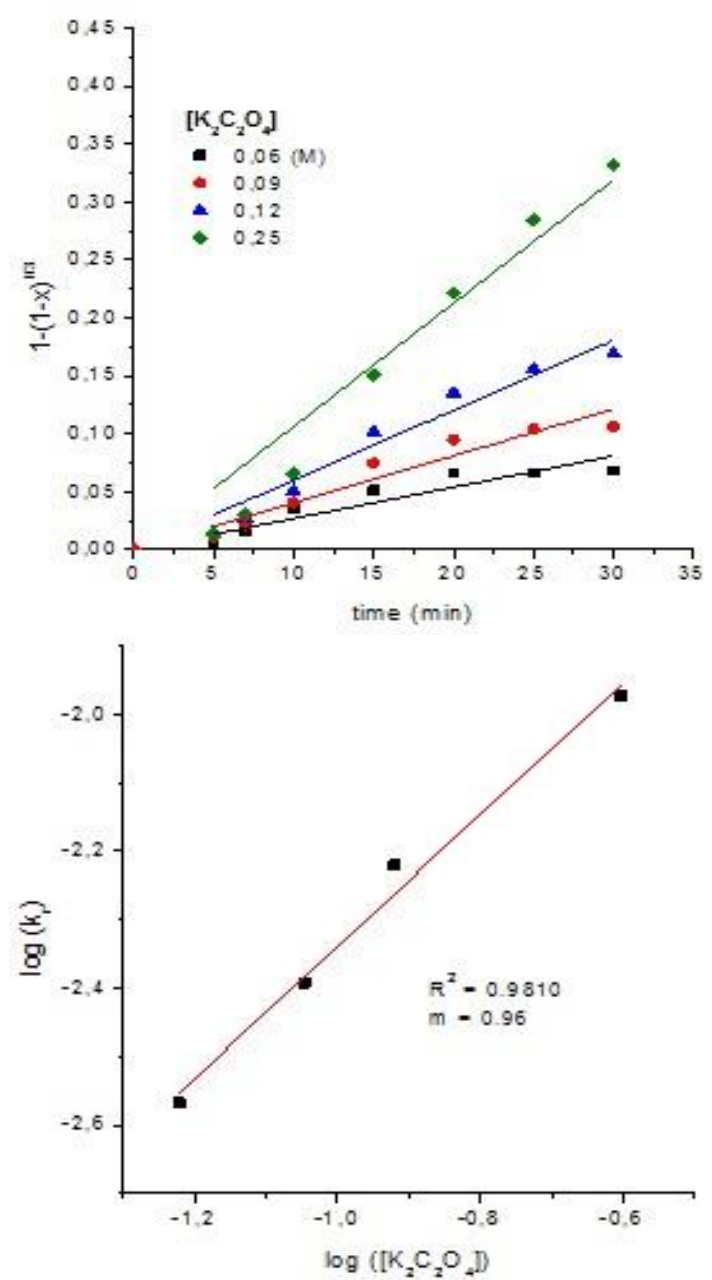

Figure 9. Plots of $1-(1-x)^{1 / 3}$ vs. time for manganese leaching at various $\left[\mathrm{K}_{2} \mathrm{C}_{2} \mathrm{O}_{4}\right]$; Determination of reaction kinetic order for pyrolusite dissolution with respect to $\mathrm{K}_{2} \mathrm{C}_{2} \mathrm{O}_{4}$; $\left[\mathrm{H}_{2} \mathrm{SO}_{4}\right]=1 \mathrm{M} ; 298^{\circ} \mathrm{K} ; \mathrm{S} / \mathrm{L}=50 \mathrm{~g} / \mathrm{L}$

Fig.10 presents the plot of $\mathrm{kr}$ versus $1 / \mathrm{r}_{0}$ and shows a linear relationship, further supporting the kinetic assumptions. The effect of the initial particle size on the values of $\mathrm{kr}$ for the dissolution of pyrolusite at $25{ }^{\circ} \mathrm{C}$ is obtained from the slopes of the lines (Fig. 10) and can be used to derive an empirical relationship whereby $\mathrm{kr}$ is proportional to $\mathrm{r}_{\mathrm{o}}^{-0.82}$. 


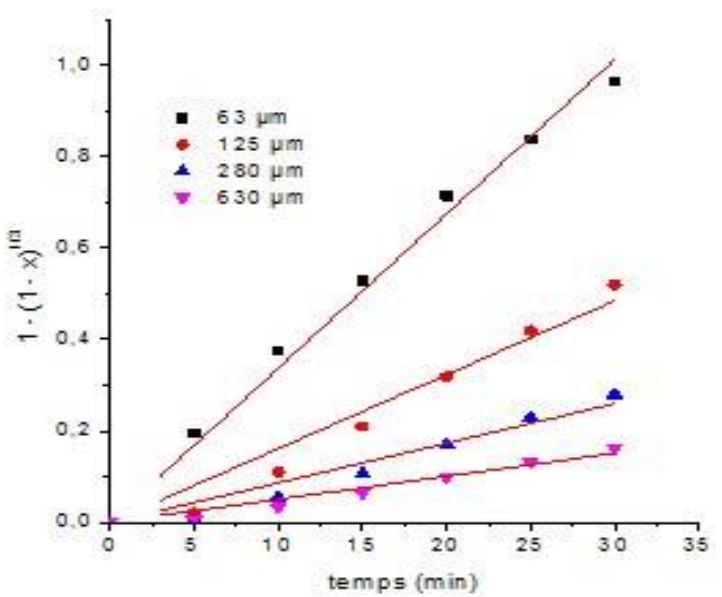

Hence, the activation energy value was determined as $(63.7 \pm 2.9) \mathrm{kJ} / \mathrm{mol}$ chemical control appears to represent the mechanism of pyrolusite leaching kinetics with $\mathrm{K}_{2} \mathrm{C}_{2} \mathrm{O}_{4}$.

Diffusion controlled heterogeneous processes are slightly dependent on temperature, while chemically controlled processes are strongly dependent on temperature.
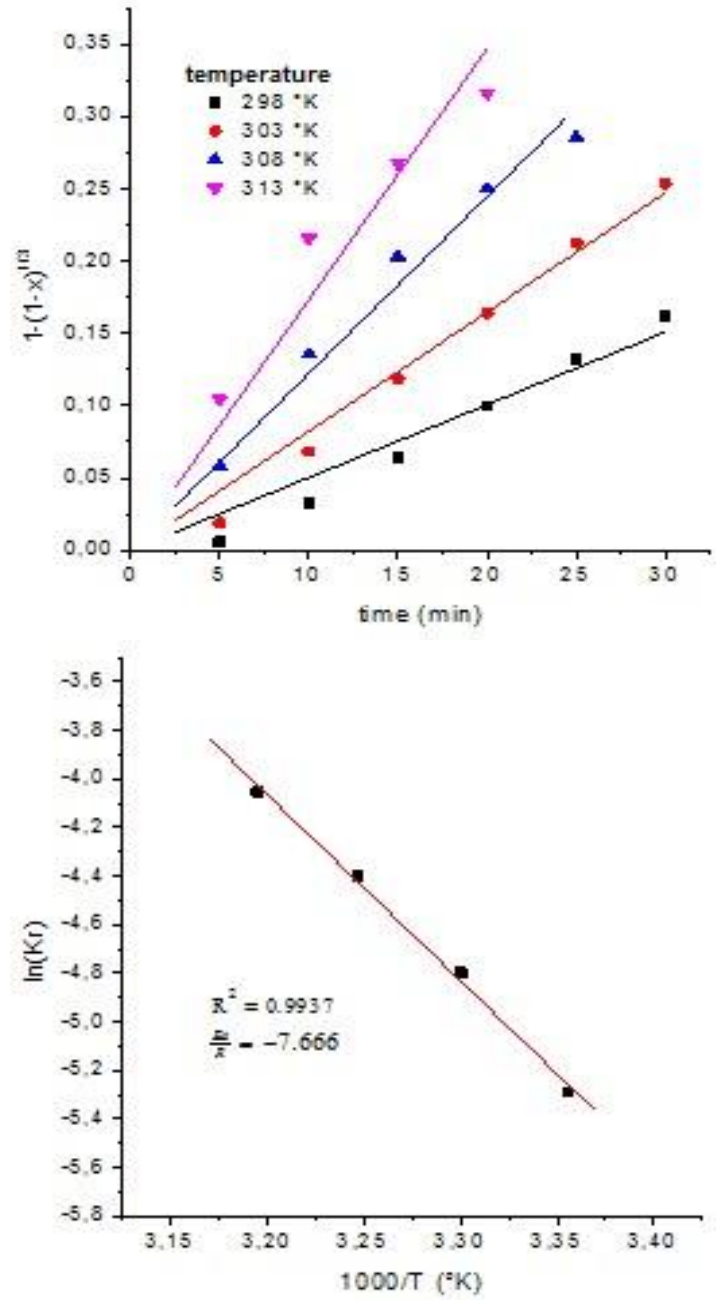

Figure 11. Plots of $1-(1-x)^{1 / 3}$ vs. time for manganese leaching at various temperature; (b)Arrhenius plot for manganese leaching in $0.5 \mathrm{H}_{2} \mathrm{SO}_{4}, 0.25 \mathrm{~K}_{2} \mathrm{C}_{2} \mathrm{O}_{4}, 50 \mathrm{~g} / \mathrm{L}$

Therefore, the value of the activation energy of a dissolution reaction may be used to predict the rate-controlling step. 
The activation energy of a diffusion controlled process is usually $21 \mathrm{~kJ} / \mathrm{mole}$ or less, when the chemical reaction is the rate controlling step the activation energy is usually in the range 40-100 kJ/mole [21, 22]. The value of the activation energy obtained in the dissolution process confirms that this leaching process is controlled by the chemical reaction.

As a result, the following kinetic expression including the parameters used in this dissolution process can be written:

$$
\begin{aligned}
& 1-(1-x)^{1 / 3}= \\
& =\frac{1.4510^{7}}{r_{0}^{0.82}} \cdot\left[\mathrm{H}_{2} \mathrm{SO}_{4}\right]^{1.07}\left[K_{2} \mathrm{C}_{2} \mathrm{O}_{4}\right]^{0.96} \exp \left(-\frac{63735}{R T}\right) \cdot t(8)
\end{aligned}
$$

To test the agreement between the experimental conversion and the values calculated from the semi-empirical model, the graph of Experimental values versus Predicted values was plotted, as shown in Fig.12. It is observed that the agreement between the experimental and the calculated values is very good.

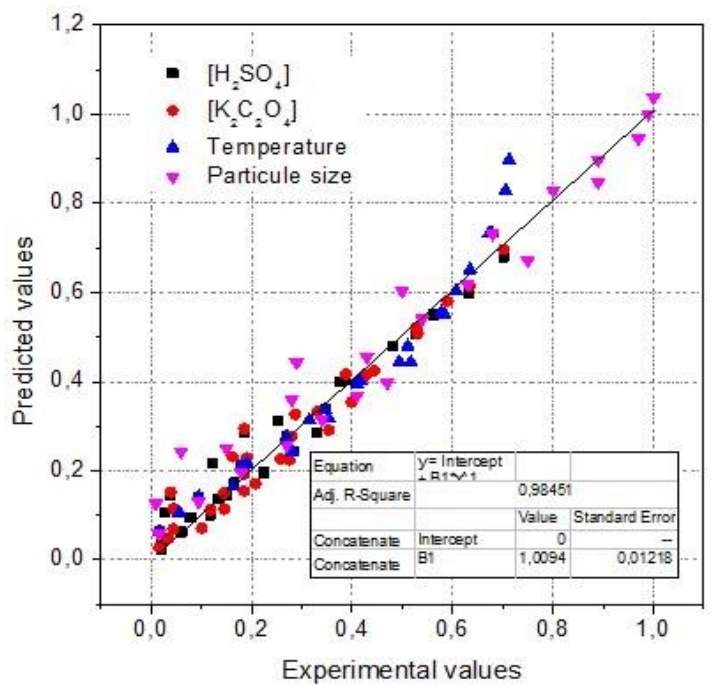

Figure 12. Plots of $1-(1-x)^{1 / 3}$ vs. time for manganese leaching at various particle size $r_{0}$; Relationship between rate constant and average initial particle size

\section{Conclusion}

The reductive leaching kinetics of pyrolusite with potassium oxalate in $\mathrm{H}_{2} \mathrm{SO}_{4}$ solution was investigated. The main parameters influencing leaching rate, such as leaching $\mathrm{H}_{2} \mathrm{SO}_{4}$ concentration, oxalate concentration, particle size and stirring speed and temperature, were studied.

The results reveal that the leaching rate increases gradually with the increase of $\mathrm{H}_{2} \mathrm{SO}_{4}$ concentration, potassium oxalate and leaching temperature and with the decrease of the size of particles. The oxalate concentration has a strong effect on the extraction $\mathrm{Mn}$ followed by temperature and sulphuric acid concentration.

The kinetic analysis shows that the leaching process is controlled by the chemical reaction of the associated minerals. The leaching process follows the kinetic model:

$1-(1-x)^{1 / 3}=$

$=\frac{1.4510^{7}}{r_{0}^{0.82}} \cdot\left[\mathrm{H}_{2} \mathrm{SO}_{4}\right]^{1.07}\left[K_{2} C_{2} O_{4}\right]^{0.96} \exp \left(-\frac{63735}{R T}\right) \cdot t$

With apparent activation energy of 63.7 $\mathrm{kJ} / \mathrm{mol}$. The experimental results also show a reaction order of 1.07 with respect to $\mathrm{H}_{2} \mathrm{SO}_{4}$ concentration and a reaction order of 0.96 with respect to potassium oxalate.

\section{Nomenclature}

A constant of the Arrhenius equation

$\mathbf{E}_{\mathrm{a}}$ apparent activation energy, $\mathrm{kJ} \cdot \mathrm{mol}^{-1}$

$\mathbf{k}_{\mathbf{0}}$ kinetic constant, $\mathrm{m}^{0.82} \cdot(\mathrm{mol} / \mathrm{L})^{-2} / \mathrm{min}^{-1}$

$\mathbf{k}_{\mathbf{m}}$ apparent rate constant when transfer and diffusion across the product layer both controls, $\min ^{-1}$

$\mathbf{k}_{\mathbf{d}}$ apparent rate constant when ash/inert solid layer diffusion controls, $\min ^{-1}$

$\mathbf{k}_{\mathbf{r}}$ apparent rate constant when chemical reaction controls, $\min ^{-1}$

$\mathbf{r}_{\mathbf{0}}$ initial radius of pyrolusite, $\mathrm{m}$

$\mathbf{R}$ gas constant, $8.314 \mathrm{~J} \cdot \mathrm{mol}^{-1} \cdot \mathrm{K}^{-1}$

t reaction time, min

$\mathrm{T}$ reaction temperature, $\mathrm{K}$

$\mathbf{x}$ fraction of reacted pyrolusite 


\section{References}

[1] Sanigok, U., Bayramoglu, M. (1988) Bench-scale manganese sulfate production from low- grade pyrolusite ores. - Part III. Chimica Acta Turcica, 16 (1): 9-20.

[2] Veglio, F., Toro, L. (1994) Fractional factorial-experiments in the development of manganese-dioxide leaching by sucrose in sulfuric-acid solutions. Hydrometallurgy, 36 (2): 215-230.

[3] Ali, E.A., Shahin, M.A., Ahmed, M.S., Ibrahim, I.A. (2002) Leaching of lowgrade Sinai manganese ore using lactose as a reductant. Egyptian Journal of Chemistry, 45 (2): 359-374.

[4] Arsent'ev, V.A., Yavorskaya, G.M., Kovaleva, O.V. (1991) Manganese recovery from oxide ores by leaching with acid, SU Patent No. 1624038.

[5] Sahoo R. N., P. K. Naik and S. C. Das (2001) Leaching of Manganese from Low-Grade Manganese Ore Using Oxalic Acid as Reductant in Sulphuric Acid Solution, Hydrometallurgy, 62: 157-163.

[6] AZIZI, et al. (2012) Trans. Nonferrous Met. Soc. China, 22: 2295-2305

[7] Stone, A.T. (1987) Microbial metabolites and the reductive dissolution of manganese oxides: oxalate and pyruvate. Geochim. Cosmochim. Acta, 51, p. 919.

[8] Acharya C, Kar R. N, Sukla L B. (2003) Studies on reaction mechanism of bioleaching of manganese ore $[\mathrm{J}]$. Minerals Engineering, 16: 1027-1030.

[9] Zhang W., Cheng Y. C. (2007a) Manganese metallurgy review. Part I: Leaching of ores/secondary materials and recovery of electrolytic/ chemical manganese dioxide $[\mathrm{J}]$. Hydrometallurgy, 89: 137-159.

[10] Zhang W., Cheng Y. C. (2007b) Manganese metallurgy review. Part II: Manganese separation and recovery from solution [J]. Hydrometallurgy, 89: 160177.

[11] Dundua R, Agniashvili G. (1999) Manganese recovery from residual slimes in the electrochemical manufacture of manganese dioxide $[\mathrm{J}]$. Proceedings of the Academy of Science of Georgia, a Series of Chemical, 25: 1-2.

[12] Petrie L M. (1995) Molecular interpretation for $\mathrm{SO}_{2}$ dissolution kinetics of pyrolusite, manganite and hematite $[\mathrm{J}]$. Appl Geochem, 10: 253-267.

[13] Alaoui A., El Kacemi K., Kitane S., El Ass K. (2013) Study of the Leaching of A Manganese Mining Residue by $\mathrm{Na}_{2} \mathrm{SO}_{3}$ in Sulfuric Acid Solution. International Journal of Engineering Research \& Technology, 2 (8).

[14] Jiang T., Yang Y. B., Huang Z. C., Qiu G. Z. (2003) Simultaneous leaching of manganese and silver from manganesesilver ores at room temperature [J]. Hydrometallurgy, 69: 177 -186.

[15] Darmane Y., Cherkaoui M., Kitane S., Alaoui A., Sebban A., Ebn Touhami M. (2008) Preparation of chemical manganese dioxide from Moroccan pyrolusite mine waste. Hydrometallurgy, 92: 73-78.

[16] Gutzmer J., Beukes NJ., Rhalmi M. \& Mukhopadhyay J. (2006) Cretaceous Karstic Cave-Fill Manganese-LeadBarium Deposits of Imini, Morocco. Economic Geology, 101, 2, 385-405.

[17] Wen, C.Y. (1968) Noncatalytic heterogeneous solid-fluid reaction models. Ind. Eng. Chem., 60: 34-54.

[18] Levenspiel, O. (1999) Chemical Reaction Engineering, 2nd Edition. John Wiley, New York.

[19] Mazet, N. (1992) Modeling of gas-solid reactions. Nonporous solids. Int. Chem. Eng., 32: 271-284. 
[20] Dickinson, C.F., Heal, G.R. (1999) Solid-liquid diffusion controlled rate equations. Thermochim. Acta, 340-341: $89-103$

[21] Abdel-Aal, E.A. (2000) Kinetics of sulfuric acid leaching of low-grade zinc silicate ore. Hydrometallurgy, 55: 247254.
[22] Ashraf, M., Zafar, Z.I., Ansari, T.M. (2005) Selective leaching kinetics and upgrading of low-grade calcareous phosphate rock in succinic acid. Hydrometallurgy, 80: 286-292. 